No.2013-03

\title{
The Price of Distance:
}

\section{Producer Heterogeneity, Pricing to Market, and Geographic Barriers}

\author{
Kazuko Kano \\ Graduate School of Economics \\ The University of Tokyo \\ Hongo 7-3-1, Bunkyo-ku \\ Tokyo, 113-0033, Japan \\ Tel: $+81-3-5841-1746$ \\ Fax: $+81-3-5841-1747$ \\ Email: kkano@e.u-tokyo.ac.jp
}

\author{
Takashi Kano \\ Graduate School of Economics \\ Hitotsubashi University \\ 2-1 Naka, Kunitachi \\ Tokyo, 186-8601, Japan \\ Tel: +81-42-580-8283 \\ Fax: +81-42-580-8283 \\ Email: tkano@econ.hit-u.ac.jp
}

\author{
Kazutaka Takechi ${ }^{\dagger}$ \\ Faculty of Economics \\ Hosei University \\ 4342 Aihara-machi, Machida-shi \\ Tokyo, 194-0298, Japan \\ Tel: +81-42-783-2566 \\ Fax: +81-42-783-2611 \\ Email: ktakechi@hosei.ac.jp
}

Current Draft: March 27, 2013

Abstract

This study investigates the effect of distance on price differentials across regions. To identify the distance effect, we need to incorporate producer heterogeneity and pricing-to-market behavior. Because geographic barriers alter the threshold levels of productivity to set a positive price across markets, the effect of distance on price differentials can be underestimated if heterogeneity and pricing to market are not accounted for. By incorporating these factors, empirical analysis using micro-level data reveals that the distance effect is significantly large, suggesting that the price of geographic barriers is still high for regional transportation.

Key Words : Law of one price; Transportation costs; Geographic barriers; Producer heterogeneity; Pricing to market

JEL Classification Number : F11, F14, F41

\footnotetext{
We would like to thank Andrew Bernard for useful discussions and the suggested title. We are also grateful to Alexandre Skiba for helpful discussions and to Masahisa Fujita, Russell Hillberry, Yuji Honjo, James Markusen, Toshiyuki Matsuura, Daisuke Miyakawa, Kiyoyasu Tanaka, Dao-Zhi Zeng and seminar participants at Chuo University, DBJ, Hosei University, Keio University, RIETI, the APTS meeting at Singapore Management University, the JEA Meeting at Kyushu Sangyo University, and the JSIE Meeting at Nanzan University for insightful comments and discussions. Financial support for this research was provided by a Grant-in-Aid for Scientific Research (No. 24530270), the Seimeikai Foundation, and the Japan Center for Economic Research.

${ }^{\dagger}$ Corresponding author.
} 


\section{Introduction}

The effect of distance on price differentials across regions is a key factor in understanding the significance of geographic barriers. Geographic separation creates price differentials across regions even in the absence of institutional differences such as tariffs, taxes, and national borders. Law of one price (LOP) studies use distance as one of the factors in trade costs to account for price differentials (Engel and Rogers, 1996; Parsley and Wei, 1996; Parsley and Wei, 2001; Crucini, Shintani, and Tsuruga, 2010). These empirical studies estimate the distance elasticity, that is, the elasticity of trade cost with respect to distance, and report a small distance effect. The distance elasticity parameter is normally less than 1 percent (0.01). However, because the distance effect is assumed to include trade costs other than transportation costs, it is not clear why the distance effect is so small and to what extent geographic barriers (transportation costs) explain price differentials.

Because the distance elasticity of transportation costs is a key parameter when assessing the impact of geographic barriers, the trade literature, such as Hummels (2007), Helpman, Melitz, and Rubinstein (2008), Crozet and Koenig (2010), and Balistreri, Hillberry, and Rutherford (2011), has tried to identify and estimate this parameter. Their empirical findings indicate that the distance elasticity tends to be larger than that in the international finance literature, which exceeds 15 percent. On the other hand, the identifi-

cation problem for the price differential effect of geographic barriers (distance) has not been examined extensively. Hence, it is an important open question whether geography is a major obstacle that raises transportation costs, and thus contributes to price differentials.

This study measures the impact of transportation costs by using price differential data. To measure transportation costs correctly using price data, as Anderson and van Wincoop (2004) point out, the difference between market prices and prices at the point of production must be used, not just two market prices. In addition, because an increase in distance causes not only increases in price differentials, but also decreases in product delivery propensity, distance causes selection biases. Thus, delivery choice to other regions (export decision) should be accounted for to control for sample selection biases, as in Helpman et al. (2008). Recent studies, in particular Donaldson (2010) and Kano, Kano, and Takechi (2013) (hereafter KKT (2013)), follow Anderson and van Wincoop's (2004) suggestion of using the price in the source region of production. Donaldson (2010) identifies the source region of salt production in India and employs this information to measure transportation costs using market prices. KKT (2013) use agricultural wholesale price data in Japan, where the source and market prices are available. They also propose an estimation procedure to take into account selection bias following Helpman et al. (2008). Because high transportation costs 
are likely to deter firms from shipping their products to a more distant market, shipment data will be truncated for more distant markets. This causes underbiases in the distance elasticity. KKT (2013) demonstrate that, if this bias is not controlled for, the distance effect is quite weak. However, if these aspects are controlled for, distance has a significant impact on price differentials.

Although these studies identify the biases in the estimation of the distance effect, the possible remaining causes of the biases, that is, producer heterogeneity and pricing to market, have not been examined in detail. Because producer heterogeneity and pricingto-market behavior cause different pricing across markets, price differentials may reflect more than just transportation costs. In KKT (2013), in which markets are monopolistically competitive, producers set invariant markups and there is no producer heterogeneity. By contrast, Donaldson (2010) uses the Eaton and Kortum (2002) model in which producer productivity is dispersed and the market is perfectly competitive. In both these studies, therefore, price differentials are characterized by transportation costs only and different pricing behavior across markets is not taken into account.

In this paper, we show that the estimates of the distance effect are underbiased if producer heterogeneity and pricing to market are ignored. We incorporate producer heterogeneity and nonhomothetic preferences in a monopolistic competition model. KKT (2013) use a CES utility function and monopolistic competition, and the price differential is a function of transportation cost only. By contrast, in a nonhomothetic preference framework, because an individual firm's pricing depends on local market characteristics (as shown by, for example, Melitz and Ottaviano, 2008), price differentials do not simply reflect transportation costs, but also include market structure (the number of products) and the productivity threshold value. Because transportation costs reduce profitability in a remote market, the productivity threshold level to set a positive price depends on transportation costs. In particular, as the productivity threshold increases, only highly productive and thus low-price-setting firms produce. Hence, ignoring producer heterogeneity creates omitted variable bias, which causes underestimation of the distance effect. Thus, we contribute to the literature by estimating the distance effect while controlling for heterogeneity and pricing to market.

By estimating the price differential equation with sample selection, producer heterogeneity, and pricing-to-market behavior taken into account, we find a large distance effect on price differentials. In the previous literature, using information on source regions, Donaldson (2010) and KKT (2013) both find a significant and moderate distance effect coefficient: 0.24 and 0.21 to 0.325 , respectively. In this study, the coefficients of the distance effect range from 0.46 to 0.768 . Although these estimates seem large, they are consistent with the results in the economic geography literature. In particular, large distance effects are found when investi- 
gating truck transportation. Because truck transportation is a major type of transportation in our analysis, our results are close to those of Combes and Lafourcade (2005), who use data on trade shipped by truck and estimate the distance elasticity to be 0.8 . Therefore, we conclude that there is a substantially large bias when producer heterogeneity and pricingto-market behavior are not incorporated. The price of geographic barriers (distance) is still high for regional transportation, even in a country with highly developed transportation infrastructure such as Japan.

The introduction of nonhomothetic preferences is essential for investigating the distance effect on price differentials with producer heterogeneity. If a CES utility function is used and thus monopolistically competitive firms set constant markup prices, the heterogeneity term will be cancelled out in the price differential equation and the price differential depends on transportation costs only. If the focus is not on individual price differentials, then important implications are obtained for aggregate price levels under firm heterogeneity using CES, because, as Ghironi and Melitz (2005) and Bergin, Glick, and Taylor (2006) show, Balassa-Samuelson effects emerge. Here, because we study individual price differentials, there is no room for producer heterogeneity in a standard CES framework. Nonhomothetic preferences lead firms to set different prices across markets, and these prices depend on a heterogeneous threshold; therefore, heterogeneity plays an important role in this analysis.

Even in a CES utility framework, pricing-to-market behavior may be taken into account. If the utility function parameter is different across markets, price differentials are a function of not only transportation costs, but also the elasticity parameter in each market. Thus, the price in each market is different. However, these elasticity parameters are not directly related to transportation costs, and can therefore be controlled for by market-specific

effects. In a nonhomothetic preference model, the thresholds are related to transportation costs; hence, the distance effect will be biased unless it is controlled for. We estimate both nonhomothetic and CES models to capture the magnitude of the bias.

This paper is organized as follows. In Section 2, we develop our nonhomothetic preference model with producer heterogeneity. For comparison, we also develop a CES model. Then, in Section 3, the empirical framework is derived and Section 4 reports the estimation results. The final section concludes.

\section{Model}

In this section, we develop a model of pricing and delivery patterns. Consumers purchase a variety of products delivered from their own and other regions. Each product is produced by a single producer. These producers are heterogeneous in terms of productivity and engage in 
monopolistic competition. Because one of the main purposes of this paper is to demonstrate the differences between cases of nonhomothetic and CES preferences, we first introduce a nonhomothetic model. Then, we consider a CES utility model for comparison.

\subsection{Consumers}

Consumer preferences are expressed by a nonhomothetic utility function. Nonhomothetic preferences have been introduced to account for pricing to market (Melitz and Ottaviano, 2008; Simonovska, 2010). We employ the Simonovska (2010) framework, which is suitable for our analysis because it enables us to make comparisons with the CES model easily. Our derivations rely on Simonovska (2010), although she focuses on trade volumes and price levels, whereas the focus here is on individual pricing across markets. 1

Consumer nonhomothetic preferences in region $i$ are expressed by:

$$
u_{i}=\int_{\omega \in \Omega} \ln \left(q_{i}(\omega)+\bar{q}\right) d \omega
$$

where $\omega$ is a variety index, $\Omega$ is the set of products available in market i, and $q_{i}(\omega)$ is consumption of variety $\omega$. The presence of $\bar{q}$ makes these preferences nonhomothetic. This represents an endowment good, which consumers cannot buy or sell (Markusen, 2010). If $\bar{q}=0$, the utility function is a typical homothetic function. The size of $\bar{q}$ can be changed, so this can be normalized to 1 as in Young (1991). Each consumer is assumed to supply one unit of labor. Thus, income is equal to wages, $w_{i}$. The budget constraint is:

$$
w_{i}=\int_{\omega \in \Omega} p_{i}(\omega) q_{i}(\omega) d \omega .
$$

Then, from utility maximization, the demand function is obtained by:

$$
q_{i}(\omega)=\frac{w_{i}+\bar{q} P_{i}}{N_{i} p_{i}(\omega)}-\bar{q}
$$

where $P_{i}=\int_{\omega \in \Omega} p_{i}(\omega)$ is the price index and $N_{i}=\int_{\omega \in \Omega} d \omega$ is the number of products in market i. This demand function has regular characteristics such that demand is decreasing in prices and increasing in income (wages). If the number of products supplied to this market rises, the demand for each product will fall. This will in turn affect producers' pricing behavior.

\subsection{Producers}

\footnotetext{
${ }^{1}$ Simonovska (2010) demonstrates how the nonhomothetic model works in general equilibrium and compares it with the CES model.
} 
Consider a producer located in region $j$. The number of potential producers is assumed to be fixed. Firms decide whether to produce and deliver the product or shut down, so this is similar to the short-run equilibrium case in Melitz and Ottaviano (2008). The timing of the delivery decision is set as follows. Producer productivity, $\phi$, is assumed to follow a random distribution, $G(\phi)$. Producers incur a fixed cost before their productivity level is realized and, based on realized productivity, they decide whether to deliver and set their optimal prices. This enables us to establish a similar delivery choice decision problem as in the CES case.

The producer profit maximization problem is to maximize variable profits, $\pi_{i j}$ :

$$
\max _{p_{i j}} \pi_{i j}=p_{i j} q_{i j}-\frac{\tau_{i j} w_{j}}{\phi} q_{i j}
$$

where $p_{i j}$ is the price in region $\mathrm{i}$ for products from region $\mathrm{j}, q_{i j}$ is the quantity of products from region $\mathrm{j}$ sold in region $\mathrm{i}$, and $\tau_{i j}$ is the iceberg-type transportation cost, $\tau_{i j}>1$ for $i \neq j$ and $\tau_{i j}=1$ for $i=j$. Because labor is assumed to be the only input, the wage rate, $w_{j}$, indicates the unit cost and $\phi$ is a measure of productivity. This productivity parameter differs among producers (firm heterogeneity). Because each product is produced by a single producer, the number of varieties is equal to the number of producers. We can denote each variety by using producer productivity and thus $\omega$ contains information of producer type (productivity) and source region $\mathrm{j}$. The optimal price set by a producer with productivity $\phi$ is:

$$
p_{i j}(\phi)=\left(\frac{\tau_{i j} w_{j}\left(w_{i}+\bar{q} P_{i}\right)}{\phi N_{i} \bar{q}}\right)^{1 / 2} .
$$

The optimal price depends on not only transportation costs, but also local market characteristics. If income in markets $\left(w_{i}\right)$ is high, producers can charge high prices. The existence of a large number of competitors means large $N_{i}$, which induces low prices because of tough competition.

In contrast to the CES preference case, if the price is sufficiently high, demand will be zero. Then, the profit for the firm in region $\mathrm{j}$ derived from supplying this product to region i will also be zero. We denote the productivity of this firm $\phi_{i j}^{*}$. Then, this threshold value is expressed by:

$$
\phi_{i j}^{*}=\frac{\tau_{i j} w_{j} N_{i} \bar{q}}{w_{i}+\bar{q} P_{i}}
$$

The threshold value, $\phi_{i j}^{*}$, is increasing in transportation costs, $\tau_{i j}$ : only high- productivity firms can overcome trade barriers. This property also holds in the CES preference case. On the other hand, market structure measured by the number of firms, $N_{i}$, influences the 
threshold value, whereas it has no effect in the CES case. This is because of variable markups in the nonhomothetic model.

Furthermore, the optimal price in the nonhomothetic case depends on market structure through $\phi_{i j}^{*}$, which means that the productivity threshold matters for each producer's price 2 In other words, aggregate producer characteristics affect individual pricing behavior in the nonhomothetic case. This requires us to account for heterogeneity and pricing to market to identify transportation costs using regional price differential data. Because of the assumption of monopolistic competition, the product index can be expressed by the producer's productivity measure: $P_{i}=\sum_{\nu} \int_{\phi_{i \nu}^{*}}^{\infty} p_{i \nu}(\phi) \mu(\phi) d \phi$ and $N_{i}=\sum_{\nu} N_{i \nu}=\sum_{\nu} \int_{\phi_{i \nu}^{*}}^{\infty} \mu(\phi) d \phi$, where $\mu$ is a conditional density function of $\phi$ conditional on delivery.

The relationship between the optimal price and the threshold value in this case is similar to that in the Melitz and Ottaviano (2008) case. Melitz and Ottaviano (2008) use a quadratic utility function and show how market size affects the key features in a model with firm heterogeneity. The optimal price is increasing in the threshold level of productivity and the number of firms is related negatively to the threshold value. Thus, many of the properties derived here are common to nonhomothetic models.

Assuming that productivity follows a Pareto distribution $\left(G(\phi)=1-b^{\theta} / \phi^{\theta}, \theta>0\right)$, the expected profit will be:

$$
E \pi_{i j}=\left(1-G\left(\phi_{i j}^{*}\right)\right) \int \pi_{i j} \mu d \phi
$$

where $\mu=g /\left(1-G\left(\phi^{*}\right)\right)=\phi^{* \theta} / \phi^{\theta+1}$. This is the conditional density where the productivity exceeds $\phi_{i j}^{*}$. Then, expected profit is calculated as follows:

$$
\left(1-G\left(\phi_{i j}^{*}\right)\right) \int \pi_{i j} \mu d \phi=\frac{b^{\theta} \tau_{i j} w_{j} \bar{q}}{(2 \theta+1)(\theta+1) \phi^{* \theta+1}} .
$$

Firms decide whether to deliver their product to region i depending on the above profit measure and fixed entry costs. This captures the self-selection problem in delivery patterns. The productivity threshold, $\phi^{*}$, affects pricing behavior and delivery choice. In our setting, even though productivity is higher than the threshold level, such firms may still choose not to deliver their products because of negative expected profits. Thus, this threshold parameter does not directly separate producers that deliver and those that do not. Rather, the threshold directly influences prices across markets.

\subsection{CES case}

\footnotetext{
${ }^{2}$ On the other hand, in the CES model, firms charge a constant markup over the marginal cost.
} 
We intend to compare our results with those for the CES utility function case. As we will see, the same implications for price differentials are derived with or without producer heterogeneity. Thus, we consider the CES model without heterogeneity for comparison with the results in $\mathrm{KKT}$ (2013).

We briefly specify a consumer's preferences using a simple CES model as follows:

$$
u_{i}=\left[\int_{\omega \in \Omega} x_{i}(\omega)^{\alpha} d \omega\right]^{1 / \alpha}
$$

Then, maximizing utility subject to the budget constraint $\left(w_{i}=\int p_{i}(\omega) q_{i}(\omega) d \omega\right)$ yields the following demand function:

$$
x_{i}=\frac{p_{i}(\omega)^{-\epsilon}}{P_{i}^{1-\epsilon}} w_{i},
$$

where $\epsilon$ is the elasticity of substitution, $\epsilon=1 /(1-\alpha)$, and $P_{i}=\left[\int_{\omega \in \Omega} p_{i}(\omega)^{1-\epsilon} d \omega\right]^{1 /(1-\epsilon)}$.

We consider a homogeneous firm in a monopolistically competitive market. The firm's profits are:

$$
\pi_{i j}=p_{j}(\omega) x_{j}(\omega)-\frac{\tau_{i j} w_{j} x_{j}(\omega)}{\phi}-f_{i j}
$$

Then, by profit maximization, the optimal price is obtained using constant markup pricing as follows:

$$
p_{i j}(\phi)=\frac{\tau_{i j} w_{j}}{\phi \alpha}
$$

Substituting this into the profit function yields:

$$
\pi_{i j}(\phi)=(1-\alpha)\left(\frac{\tau_{i j} w_{j}}{\alpha P_{i} \phi}\right)^{1-\epsilon} w_{i}
$$

Because firms are assumed to be homogeneous, their decision to deliver does not depend on a randomly selected level of productivity. Rather, the choice is based on the comparison of profits and fixed cost of delivery. If $\pi_{i j} / f_{i j}>1$, then firms in region $\mathrm{j}$ will deliver their products to region i. Thus, similarly to the heterogeneous firm case, delivery data are truncated because of self-selection by the producers.

This break-even productivity level depends on transportation costs. If transportation costs, $\tau_{i j}$, are high, firms that are productive enough are able to make positive profits: $\phi_{i j}$ is increasing in $\tau_{i j}$. However, as mentioned, market structure does not affect $\phi_{i j}$ directly, but only through the price index, $P_{i}$.

\subsection{Price differentials}


Our approach of taking the difference between the price in markets and that in source regions allows us to measure transportation costs accurately. Because retail prices do not consider information about the source, taking the difference between two market prices does not necessarily enable the measurement of transportation costs. However, if the source price and the market price with information about the source are available, the difference between these prices captures the costs of transportation. This idea can be highlighted in a CES utility framework. The price differential is:

$$
p_{i j} / p_{j j}=\tau_{i j}
$$

In contrast to the nonhomothetic case, as we will see, price differentials in the CES case are independent of market characteristics. This is because the productivity threshold level does not affect individual pricing. The thresholds are derived from the zero-profit conditions and determine not prices but the selection of producers that deliver. As a result, when obtaining price differentials, market characteristic variables are cancelled out.

In the nonhomothetic model, using the optimal prices set by firms, the price differential between market and source is:

$$
p_{i j} / p_{j j}=\tau_{i j} \phi_{j j}^{* 1 / 2} / \phi_{i j}^{* 1 / 2} .
$$

Because the threshold value, $\phi_{i j}^{*}$, depends on transportation costs, ignoring producer heterogeneity causes biases in identifying the relationship between the price differential and transportation costs. If $\tau_{i j}$ increases, $\phi_{i j}^{*}$ will increase. Because $\phi_{j j}^{*}$ does not depend on $\tau_{i j}$, a larger $\phi_{i j}^{*}$ induces a smaller price differential. Thus, heterogeneity reduces the price differential. This omitted variable bias may cause underestimation of the effect of transportation costs.

In addition, $\phi_{i j}^{*}$ depends on the number of firms, $N_{i}$. This is a function of the threshold value itself and thus is affected by transportation costs. Hence, the changes in $\tau_{i j}$ are associated with the changes in market structure. This implies that market prices are set depending on market structure and, therefore, the number of firms across markets is a determinant of price differentials. If this type of pricing-to-market behavior is not controlled for, the estimates of transportation costs will be biased.

As we mentioned, one of our objectives in this paper is to highlight the changes by incorporating firm heterogeneity. As a matter of fact, equation (9) holds with and without producer heterogeneity. This is because even if firms' productivity is heterogeneous, optimal pricing does not depend on the threshold value of productivity, which is a key factor of heterogeneity. Besides, each firm's productivity is cancelled out when considering price differentials. Hence, producer heterogeneity does not play an important role in the link between 
price differentials and transportation costs in a CES model. Producer heterogeneity matters for the link between price differentials and distance not when preferences are CES, but when they are nonhomothetic. If we introduce nonhomothetic preferences, firms set variable markups across markets in the setting of optimal prices and thus we deal with pricing-tomarket behavior. Therefore, the bias caused by producer heterogeneity is indispensable for pricing to market.

As mentioned in the Introduction, even in a CES model, pricing-to-market behavior can be taken into account by introducing demand parameter heterogeneity across markets. That is, if the elasticity of substitution parameter differs across markets, the price differential will be:

$$
p_{i j} / p_{j j}=\tau_{i j}\left(\alpha_{j} / \alpha_{i}\right)
$$

where $\alpha_{i}$ and $\alpha_{j}$ are demand parameters in the CES utility function. However, these can be controlled for by using region-specific effects and have nothing to do with the transportation $\operatorname{cost}, \tau_{i j}$. Hence, this does not cause any biases in the estimation of the distance effect.

By using the formula for the threshold value in the nonhomothetic model, $\phi_{i j}^{*}$, we are able to express the price differential as follows:

$$
p_{i j} / p_{j j}=\tau_{i j}^{1 / 2} \frac{\left(w_{i}+\bar{q} P_{i}\right)^{1 / 2}}{\left(w_{j}+\bar{q} P_{j}\right)^{1 / 2}}\left(\frac{N_{j}}{N_{i}}\right)^{1 / 2} .
$$

The heterogeneity effect reduces the direct impact of transportation costs from $\tau_{i j}$ to $\tau_{i j}^{1 / 2}$ in our nonhomothetic specification. In general, the effect of transportation costs will also be weakened in a nonhomothetic specification because the effect of a transportation cost increase on price differentials is mitigated by the producer selection. In the presence of high transportation costs, only high-productivity firms are able to ship their products. Such firms set their prices at a low level. Thus, the greater the distance between markets, the lower is the magnitude of the increase in prices. This mechanism creates underbias in the distance elasticity when only the price differential data are used.

This selection mechanism operates at the individual pricing level. This mechanism also influences average price changes associated with general productivity shocks, as Ghironi and Melitz (2005) and Atkeson and Burstein (2008) show. If only high-productivity firms can export because of negative shocks, then, because they set the price at a low level, the average price will be low. If free entry is assumed, firm exit because of negative shocks will cause labor demand to decrease and thus labor costs to decrease. This enables low-productivity firms to export, implying an increase in the average export price. Thus, depending on the entry condition assumptions, the average price either increases or decreases. In our study, 
because we do not consider free entry, negative shocks will decrease individual prices set in the market.

Other factors that affect the price differentials are source, market characteristics, and market structure. If these factors are correlated with transportation costs, omitted variable biases occur. Taking the log of the above equation yields:

$$
\begin{aligned}
\ln p_{i j}-\ln p_{j j}=(1 / 2) \ln \tau_{i j}+(1 / 2) \ln N_{j} & -(1 / 2) \ln N_{i} \\
& +(1 / 2) \ln \left(w_{i}+\bar{q} P_{i}\right)-(1 / 2) \ln \left(w_{j}+\bar{q} P_{j}\right)
\end{aligned}
$$

The price differential depends on not only transportation costs, but also market characteristics, such as the number of products and price indices. This property reflects the pricingto-market behavior. Because the optimal price depends on local market characteristics, the price differentials reflect market structure. The ability to capture this element is an advantage of the nonhomothetic model over the CES framework.

So far, we have not imposed any functional form on transportation costs. We adopt the following conventional specification:

$$
\tau_{i j}=D_{i j}^{\gamma} e^{\mu+u_{i j}}
$$

where $D_{i j}$ is the distance between two regions. That is, if $\gamma>0$, then as distance increases, transportation costs increase. The constant term $\mu$ corresponds to the uniform transportation costs component and $u_{i j}$ denotes unobservable transportation costs, $u_{i j} \sim N\left(0, \sigma_{u}\right)$. The $\log$ form is:

$$
\ln \tau_{i j}=\gamma \ln D_{i j}+\mu+u_{i j}
$$

The distance elasticity, $\gamma$, is our main parameter. Identifying this parameter is important if delivery choice, producer heterogeneity, and pricing to market are to be accounted for.

Regarding the threshold value $\left(\phi_{i j}^{*}\right)$, even if $\phi_{i j}^{*}<\phi$, the producer with productivity $\phi$ may not deliver its product because demand is too low to cover fixed costs. Thus, producer heterogeneity (threshold value $\phi^{*}$ ) matters mainly for the individual pricing decision, and not for the delivery decision. We take the delivery decision into account by considering the sample selection problem caused by the positive profit condition.

\subsection{Delivery choice}

The price differential is observed only when there is an actual delivery. Thus, there will be a data truncation problem. As the delivery choice is made based on profitability, we 
consider the producer's delivery decision. Because producers pay $f_{i j}$, the delivery decision is summarized by the variable $Z_{i j}$ :

$$
Z_{i j}=\frac{\frac{b^{\theta} \tau_{i j} w_{j} \bar{q}}{(2 \theta+1)(\theta+1) \phi_{i j}^{*}{ }^{\theta+1}}}{f_{i j}} .
$$

Thus, if $Z_{i j}$ is greater than 1 , firms in region $\mathrm{j}$ choose to deliver the product to region i. By taking logs, we have the following delivery choice equation:

$$
\begin{aligned}
\ln Z_{i j} & =\theta \ln b+\ln \tau_{i j}+\ln w_{j}+\ln \bar{q}-\ln (2 \theta+1)(\theta+1)-(\theta+1) \ln \phi_{i j}^{*}-\ln f_{i j} \\
& =\theta \ln b-\theta \ln \tau_{i j}-\theta \ln w_{j}-\theta \ln \bar{q}-\ln (2 \theta+1)(\theta+1) \\
& -(\theta+1) \ln N_{i}+(\theta+1) \ln \left(w_{i}+\bar{q} P_{i}\right)-\ln f_{i j} .
\end{aligned}
$$

If $\ln Z_{i j}>0$, then delivery from $\mathrm{j}$ to $\mathrm{i}$ will take place. Because the price differential is observed only when $\ln Z_{i j}>0$, we take into account this selection bias to estimate the price differential equation. We estimate the price differential and delivery choice equations jointly.

Similarly, in the CES framework, the delivery choice is expressed by $Z_{i j}$ :

$$
Z_{i j}=\frac{(1-\alpha)\left[\frac{\tau_{i j} w_{j}}{\alpha P_{i} \phi}\right]^{1-\epsilon} w_{i}}{f_{i j}}
$$

Thus, taking logs yields a similar expression for delivery choice:

$$
\begin{aligned}
\ln Z_{i j}=z_{i j}=\ln (1-\alpha)+(1-\epsilon) & \ln \tau_{i j}+(1-\epsilon) \ln w_{j} \\
& -(1-\epsilon) \ln \alpha-(1-\epsilon) \ln P_{i}-(1-\epsilon) \ln \phi+\ln w_{i}-\ln f_{i j} .
\end{aligned}
$$

Our focus is on the individual firm's choice of prices, rather than on trade volume as in Helpman et al. (2008). Thus, it is not necessary to control for the effect of heterogeneity on aggregate variables. Rather, we need to account for the impact of heterogeneity on the individual firm's pricing across markets and its delivery choice according to this selection mechanism.

Similarly to the nonhomothetic preference case, we estimate the price differential equation taking this selection bias into account. Whereas the KKT (2013) model is estimated using an instrumental variable approach, controlling for selection bias is based on this delivery choice equation. Thus, in this paper, we simply estimate the price differential and delivery choice equations by maximum likelihood. We use regional dummies to control for marketspecific effects such as price indices (Anderson and van Wincoop, 2003; Helpman et al., 2008). 


\subsection{Empirical specification}

For the estimation, we need to parameterize the price differential and delivery choice equations. As in Helpman et al. (2008), fixed costs have the following specification: $f_{i j}=$ $\exp \left(\lambda_{i}+\lambda_{j}-\nu_{i j}\right)$. The estimating equations are expressed as follows:

$$
\begin{aligned}
& z_{i j}=-\ln f_{i j}+\theta(\ln b-\bar{q})-\theta \mu-\theta u_{i j}-\ln (2 \theta+1)(\theta+1) \\
&-\theta \gamma \ln D_{i j}-\theta \ln w_{j}-(\theta+1) \ln N_{i}+(\theta+1) \ln \left(w_{i}+\bar{q} P_{i}\right) \\
&=c_{0}+c_{1}-\theta \gamma \ln D_{i j}-\theta \ln w_{j}-(\theta+1) \ln N_{i}+\left(\theta+1+c_{2}\right) d u m_{i}+c_{3} d u m_{j}+\eta_{i j},
\end{aligned}
$$

where $c_{0}=-\theta \mu-\ln (2 \theta+1)(\theta+1), c_{1}=\theta(\ln b-\bar{q}), \ln \left(w_{i}+\bar{q} P_{i}\right)-\lambda_{i}$ is captured by region i's specific effect; therefore, $(\theta+1) \ln \left(w_{i}+\bar{q} P_{i}\right)-\lambda_{i}=\left(\theta+1+c_{2}\right) d u m_{i}$, and $d_{u m_{i}}$ is region i's specific effect. The number of products may be a noisy variable or the method by which the number of products is introduced may be misspecified; therefore, we use $\chi \ln N_{i}$ instead of $\ln N_{i}$ in estimations, where $\chi$ is a free parameter. The error term is $\eta_{i j}=-\theta u_{i j}+\nu_{i j} \sim$ $N\left(0, \theta^{2} \sigma_{u}^{2}+\sigma_{\nu}^{2}\right)$.

Similarly, the price differential equation is:

$$
\begin{aligned}
& q_{i j}=\ln p_{i j}-\ln p_{j j} \\
& =(1 / 2) \mu+(1 / 2) \gamma \ln D_{i j}+(1 / 2) \ln N_{j}-(1 / 2) \ln N_{i}+c_{4} d u m_{j}-c_{5} d u m_{i}+(1 / 2) u_{i j}
\end{aligned}
$$

where $d u m_{j}$ controls for region-specific effects including wages and price indices, as in the delivery choice equation. Because of pricing to market, the disturbance term is modified to $u_{i j} / 2$. Thus, not only are the covariates different from the CES case, but the shape of the price differential distribution is different also.

As in KKT (2013), with regard to the identification of the distance elasticity, $\gamma$, the price differential and product delivery equations reveal an important result. Simply estimating the price differential equation only may lead to underestimation of $\gamma$. This is because the errors in these equations are correlated: because $\eta_{i j}=-\theta u_{i j}+\nu_{i j}$, the error terms $\eta_{i j}$ and $u_{i j}$ are correlated. As shown by Helpman et al. (2008), taking the conditional expectation of $q_{i j}$ yields: $E\left[q_{i j} \mid X\right]=(1 / 2) \mu+(1 / 2) \gamma \ln D_{i j}+(1 / 2) \ln \left(1+N_{i}\right)-(1 / 2) \ln \left(1+N_{j}\right)+c_{4} d u m_{j}-$ $c_{5} d u m_{i}+(1 / 2) E\left[u_{i j} \mid X\right]$, where $X$ is a vector of observables. Because $E\left[u_{i j} \mid X\right]=\rho \frac{\sigma_{u}}{\sigma_{\eta}} E\left[\eta_{i j} \mid X\right]$, if we ignore this correlation, there will be bias in the estimate of the distance effect. 3 This bias term is expressed as an inverse Mills ratio: $E\left[\eta_{i j} \mid X\right]=\phi\left(\hat{z}_{i j}\right) / \Phi\left(\hat{z}_{i j}\right)$. Hence, to obtain consistent estimates, we need to account for the correlation between the price differential

\footnotetext{
${ }^{3}$ Because $u$ and $\nu$ are orthogonal, $E[\eta u]=E[(-\theta u+\nu) u]=-\theta \sigma_{u}^{2}$. The correlation $\rho$ is defined by $\rho=\sigma_{\eta u} / \sigma_{u}$. Thus, $\sigma_{\eta u}=\rho \sigma_{u}=-\theta \sigma_{u}^{2}$. Then, $\sigma_{u}=-\rho / \theta$.
} 
and delivery choice equations; the significance of sample selection relies on this correlation parameter, $\rho$.

To take into consideration this selection effect, we employ a full information maximum likelihood (FIML) approach. We assume that the distribution of the errors is joint normal. The log-likelihood function is:

$$
\begin{aligned}
L=\sum_{i, j} & \left(1-T_{i j}\right) \ln \left[\Phi\left(-W_{1 i j}\right)\right]+\sum_{i, j} T_{i j} \ln \left[\Phi\left(\frac{W_{1 i j}+2 \rho \sigma_{u}^{-1}\left(W_{2 i j}\right)}{\left(1-\rho^{2}\right)^{1 / 2}}\right)\right] \\
& +\sum_{i, j} T_{i j} \ln \phi\left(\frac{W_{2 i j}}{\left(\sigma_{u} / 2\right)}\right)-\sum_{i, j} T_{i j} \ln \left(\sigma_{u} / 2\right),
\end{aligned}
$$

where $W_{1 i j}=c_{0}+c_{1}+\theta \gamma \ln D_{i j}+\theta \ln w_{j}+(\theta+1) \chi_{1} \ln N_{i}+\left(\theta+1+c_{2}\right) d u m_{i}+c_{3} d u m_{j}$ and $W_{2 i j}=q_{i j}-(1 / 2) \mu-(1 / 2) \gamma \ln D_{i j}-(1 / 2) \chi_{2} \ln N_{j}+(1 / 2) \chi_{3} \ln N_{i}-c_{4} d u m_{j}-c_{5} d u m_{i}$. Using FIML has several advantages: it is efficient, it allows us to examine delivery choice, and it can detect unobservable factors driving self-selection bias in an explicit way. However, our approach has the disadvantage of possible misspecification; we address this misspecification issue by doing diagnosis checks.

In the case of CES utility without producer heterogeneity, the estimating equation is:

$$
z_{i j}=\beta-(\epsilon-1) \gamma d_{j i}+(\epsilon-1) \ln P_{i}+(1-\epsilon) \ln w_{j}+\ln w_{i}+\xi_{j}+\omega_{l}+\lambda_{i}+\eta_{i j}
$$

where $\beta=-\epsilon \ln \epsilon-(1-\epsilon) \ln (\epsilon-1)+(1-\epsilon) \mu, \omega_{l}=(1-\epsilon) \phi$, and $\eta_{i j}=(1-\epsilon) u_{i j}+\nu_{i j}$. The price differential equation is:

$$
q_{i j}=\mu+\gamma d_{i j}+c_{6} d u m_{i}+c_{7} d u m_{j}+u_{i j}
$$

Then, the log-likelihood function is as follows:

$$
\begin{aligned}
L=\sum_{i, j}(1 & \left.-T_{i j}\right) \ln \left[\Phi\left(-W_{3 i j}\right)\right]+\sum_{i, j} T_{i j} \ln \left[\Phi\left(\frac{W_{3 i j}+\rho \sigma_{u}^{-1}\left(W_{4 i j}\right)}{\left(1-\rho^{2}\right)^{1 / 2}}\right)\right] \\
& +\sum_{i, j} T_{i j} \ln \phi\left(\frac{W_{4 i j}}{\sigma_{u}}\right)-\sum_{i, j} T_{i j} \ln \sigma_{u}
\end{aligned}
$$

where $W_{3 i j}=\beta-(\epsilon-1) \gamma d_{j i}+(\epsilon-1) \ln P_{i}+(1-\epsilon) \ln w_{j}+\ln w_{i}+\xi_{j}+\omega_{l}+\lambda_{i}$ and $W_{4 i j}=q_{i j}-\mu-\gamma d_{i j}$. We use the consumer price index as the price index, and the use of region-specific effects controls for other region-specific factors.

These two empirical models, namely the nonhomothetic model and the CES model, account for the data truncation problem caused by the self-selection of producers. The main difference between these approaches is in the price differential equation. In the CES case, it 
is simply a function of distance. In the nonhomothetic case, the effect of distance is different, and there are local market characteristics, which reflect producer heterogeneity and pricingto-market behavior. We apply our model to the price and delivery data to find the distance elasticity.

\section{Data}

We apply our approach to data on wholesale prices of individual goods and delivery patterns across regions. Using wholesale prices enables us to focus on transportation costs because retail prices include local distribution costs. The individual goods are agricultural products in Japan. As the wholesale prices of agricultural products in source regions and markets are available, the price differential between market and source prices can be used to measure transportation costs properly.

The data source for wholesale prices is the Daily Wholesale Market Information on Fresh Fruit and Vegetables ("Seikabutsu Hinmokubetsu Shikyo Joho" in Japanese). The data set is collected by the Center for Fresh Food Market Information Services ("Zenkoku Seisen Syokuryohin Ryutsu Joho Senta"; URL: www2s.biglobe.ne.jp/fains/index.html), which provides data on almost all transactions at 55 wholesale markets operating daily in the 47 prefectures of Japan. Each prefecture has at least one wholesale market, so the data variation is nationwide. This daily market survey covers the wholesale prices of 120 different fruits and vegetables.

Each agricultural product is further categorized by variety, size, and grade, as well as by producing prefecture. Hence, for example, the data set reports the wholesale prices of potatoes at six wholesale markets of the "Dansyaku (Irish Cobbler equivalent)" variety, size "L", with grade "Syu (excellent)" produced in "Hokkaido" Prefecture on September 7, 2007. Because prices depend on characteristics, each combination of characteristics is identified as the same product. This high degree of categorization is important because the LOP requires a comparison of the prices of identical goods to infer transportation costs precisely. We focus on eight vegetables: cabbages, carrots, Chinese cabbages (c-cabbages, hereafter), lettuce, shiitake mushrooms (s-mushrooms, hereafter), spinach, potatoes, and Welsh onions. In this paper, we examine the 2007 survey that reports the market transactions for a period of 274 days. Thus, the unit of measurement for the sample is source-market price differentials of the same product on a given trading day.

The price reported in each market has three forms: the highest price, the mode price, and the lowest price. Most markets record all three prices, but several markets report only the highest and the lowest prices or only the mode price. Thus, we construct our price variable by 
averaging these price variables. We use the mode price when this is the only price available. The transaction unit of measurement for each product is also reported. To obtain the same unit of measurement for each product, we divide the price by the number of transaction units (kilograms). Table 1 summarizes several descriptive statistics for these products. The first row reports the average price per kilogram (1 kilogram = approximately 2.2 pounds). S-mushrooms are the most expensive, at 1113.627 yen (approximately 13 US dollars), and the cheapest are c-cabbages, which are 61.628 yen (approximately 0.9 US dollars).

Table 1 also shows that each product is highly categorized by product variety, size, and grade. The numbers of distinct products are large: 1,207 for cabbages; 1,186 for carrots; 1,001 for c-cabbages; 903 for lettuce; 1,423 for potatoes; 909 for s-mushrooms; 551 for spinach; and 1,115 for Welsh onions. For each product entry l, we count the number of deliveries as $T_{i j}(l)=1$ and nondeliveries as $T_{i j}(l)=0$ only for the dates on which the product is traded at the wholesale market in producing prefecture $j$. We identify product delivery $T_{i j}(l)=1$ if the data report that the source prefecture of product entry l sold in consuming region $\mathrm{i}$ is region $\mathrm{j}$. The price differential is constructed by subtracting the wholesale price in producing prefecture $\mathrm{j}, p_{j}(\omega)$, from that in consuming prefecture $\mathrm{i}, p_{i}(\omega)$. If the sample of $q_{i j}(\omega)$ is available, this means that $T_{i j}(\omega)=1$ for pair $(\mathrm{i}, \mathrm{j})$.

The bottom part of Table 1 reports that the total number of both delivery and nondelivery observations across all products is greater than 190,000 for each vegetable. We use this as the number of observations in our FIML estimation. Out of the total number of delivery and nondelivery cases, the number of delivery cases is relatively small, at approximately 10,000 for each vegetable. Our data set, therefore, indicates that product delivery is quite limited. Many products are delivered only locally; for example, carrots are produced in every prefecture and shipped to own-prefecture markets. Only agriculture-intensive prefectures such as Hokkaido ship to remote markets. Thus, the data truncation issue is quite important in this sample.

The other data we use in this paper are obtained as follows. The geographic distance between prefectural pair $(i, j)$ is approximated by the distance between the prefectural head offices located in the prefectural capital cities. The distance data are provided by the GSI and are publicly available on the GSI website.4 We use daily temperature to control for supply and demand shocks. The daily temperature data are reported by the Japan Meteorological Agency, from whose website we download them. 5 Finally, we use monthly data on scheduled cash earnings for wages, which are reported in the Monthly Labour Survey ("Maitsuki Kinrou

\footnotetext{
${ }^{4}$ www.gsi.go.jp/kokujyoho/kenchokan.html

${ }^{5}$ www.data.jma.go.jp/obd/stats/etrn/index.php
} 
Tokei Chosa") conducted by the Ministry of Health, Labour, and Welfare 6

One verification strategy when introducing a nonhomothetic preference is to check whether high-quality (and therefore high-price) goods are sold in high- income markets. We use the data on wholesale market prices and scheduled cash earnings to check for a positive correlation between these. Figure 1 places each prefecture's wages on the vertical axis and vegetable prices on the horizontal axis. All data variations reveal a positive relationship between incomes and prices, as shown by the solid line with positive slope. This indicates that high-income regions tend to consume high- quality (price) goods, suggesting that our nonhomothetic preference specification is consistent with a certain characteristic in our data.

\section{Estimation results}

Table 2 reports the estimation results, with the main results reported in the top half. For comparison, the results using the CES utility function and the simple regression results are reported in the bottom half of Table 2. The distance elasticity in the nonhomothetic framework ranges from 0.46 (cabbages) to 0.768 (s-mushrooms). This indicates that when the shipment distance from origin to destination increases by 1 percent, the price differential increases by about 0.5 percent. These values for the distance elasticity are larger than those in previous studies, which implies the presence of an underbias of the distance elasticity in previous studies. As in previous studies, if we use two market prices to construct price differentials and regress these on distance, then the distance effect coefficient is at most 0.05. That is, even if the distance is doubled, the price differential increases by only 5 percent. Thus, even using our data, regressing only the price differential (not identifying the source region) on distance, which is the conventional method in the literature, yields similar results. The results of the CES utility function are similar to those in KKT (2013). As in KKT (2013), and following Anderson and van Wincoop (2004), the price differential measure is the difference between the market price and the price in the producing prefecture. Delivery choice is modeled explicitly to control for sample selection. One difference in estimations between this study and KKT (2013) is that they propose an instrumental variable approach for the structural estimation. Although the results of the CES framework indicate significantly large distance effects of 0.287 to 0.49 , these are smaller than those of the nonhomothetic model.

When incorporating producer heterogeneity and pricing to market, the results under nonhomothetic preferences indicate a much larger distance effect compared with both a simple regression and the CES framework; the CES results, in turn, are larger than the conventional OLS results. The results under nonhomothetic preferences are found to be even

\footnotetext{
${ }^{6}$ The data are available at www.mhlw.go.jp/toukei/list/30-1.html.
} 
larger than the CES case. This is consistent with our argument that producer heterogeneity affects the pricing decision in each market and thus causes underbias in the distance elasticity estimates. This is because transportation costs induce only productive firms to deliver products, and these firms can charge a low price. Large distance elasticity estimates also imply that geographic barriers influence delivery choice. The probability of delivery will be reduced by an increase in transportation costs. Thus, the presence of large distance effects after accounting for producer heterogeneity suggests that the price of geographic barriers is still high for regional transportation.

Another important parameter in our estimations is the heterogeneity parameter, $\theta$. Our estimates range from 1.169 to 2.329. A small $\theta$ means that there is a large dispersion in productivity. These estimates can be considered to be small (producer heterogeneity is highly dispersed). This may be because farmers in Japan are quite heterogeneous. Small farms operated by elderly people in suburban areas produce agricultural products, whereas agriculture-intensive prefectures such as Hokkaido are home to large-scale farms. In 2009, the average area under cultivation for each farm in Hokkaido Prefecture was 20.50 hectares (approximately 50.66 acres), compared with an average area of 1.41 hectares (approximately 3.48 acres) in other prefectures 7 These farms may deliver their products to the same markets. In our framework, all prefectures have the same productivity distribution, so the low value of $\theta$ may reflect this dispersion among farms. In fact, in Table 2, the estimates obtained using carrots and potatoes have small values of $\theta$. Because Hokkaido is known to be a highproductivity region for these products, the presence of heterogeneous suppliers gives us large dispersion results.

The heterogeneity parameter, $\theta$, has been investigated extensively in the trade literature. In the Eaton and Kortum (2002) framework, this is the elasticity of the trade parameter, which is a crucial parameter for welfare gain analysis from trade (Arkolakis, Costinot, and Rodriguez-Clare, 2012). Eaton and Kortum (2002) estimate this parameter to be 8.28, Bernard, Eaton, Jensen, and Kortum (2003) estimate it to be 3.6, Crozet and Koenig (2010) estimate it to be from 1.65 to 7.31, Simonovska and Waugh (2010) use the simulated method of moments to obtain estimates from 3.57 to 4.46, and Balistreri et al. (2011) estimate it to be from 3.924 to 5.171. Donaldson (2010) uses the Eaton and Kortum (2002) model to estimate the productivity variability parameter, and estimates an average value of 3.8. As in Donaldson (2010), we use price data to estimate two crucial parameters in the producer heterogeneity model. Our estimates are lower than these other studies, possibly because the more disaggregated the product level is, the higher the dispersion of heterogeneity. Our sample contains disaggregated product-level data and has a quite fine

\footnotetext{
${ }^{7}$ www.maff.go.jp/j/tokei/sihyo/index.html.
} 
categorization; as such, our estimates report a small $\theta$.

The correlation parameter $\rho$ is also important for the significance of sample selection. These estimates range from -0.624 to -0.868 . All results are negative and statistically significant. Hence, to identify the true parameter, controlling for selectivity bias is crucial. A positive shock that increases the price differentials caused by transportation costs (for example, a fuel price increase) will also decrease the probability of delivery. Without controlling for this negative correlation caused by unobservable shocks, as we have seen, the distance effects are found to be small. We detect the existence of such a negative effect.

The relevance of the estimates depends on the empirical validity of our model. For model validation purposes, we conduct diagnostic checks of our model with respect to two important aspects of the actual data: the pattern of product delivery and the association of price differentials with delivery distances. First, we calculate the percentage correctly predicted (PCPs) measures for $T_{i j}(l)=0$ or 1 . To construct the PCPs, we calculate the predicted conditional probabilities and the predicted delivery index where the predicted probabilities are greater than 0.5. The results are reported in the bottom row of Table 2 . The PCPs are all greater than 0.96, which suggests that our model successfully predicts actual delivery patterns.

The second diagnosis concerns price differentials with respect to delivery distances. The question is whether our sample-selection model predicts the actual price differentials. To conduct this diagnosis check, we derive the prediction of the model for price differentials with the selection bias controlled for. Each panel in Figure 2 plots the resulting predicted price differentials (dots), as well as the data counterparts (crosses), against the corresponding log distances for each vegetable. The dots are distributed inside the cloud formed by the crosses in all panels. This means that our model successfully predicts the relationship between the price differentials and distances overall.

One issue remaining when comparing the results of the nonhomothetic and CES models is the elasticity of substitution parameter, $\epsilon$. In the nonhomothetic preference model, the utility function is in log form to obtain an explicit solution for the optimal price. Because the coefficient of distance in the selection equation is $\theta \gamma$ in the nonhomothetic case and $(\epsilon-$ 1) $\gamma$ in the CES model, ignoring the elasticity of substitution may cause small estimates of $\theta$ and large estimates of $\gamma$. If this composite remains constant, a small elasticity of substitution may imply a large distance effect. The identification of these parameters separately requires a model that incorporates both the dispersion and elasticity of substitution components. This is a limitation of our study and an important issue for future research.

\section{Concluding remarks}


We have investigated the impact of producer heterogeneity and pricing-to-market behavior on the distance elasticity in regional price differentials. Because producer heterogeneity is not treated as crucial in the identification of the distance effect in a conventional CES utility framework, we developed a nonhomothetic preference model, thus incorporating pricing-to-market behavior.

Our empirical analysis showed that ignoring these factors causes underestimation in the CES utility framework. The distance effect is significantly large for regional price differentials. These results suggest that the price of geographic barriers is still high for regional transportation. Even though Japan is considered to have well-established infrastructure and a sophisticated logistics system, the geographic barriers are large enough to create substantial price differentials. Thus, in a country with poor transportation facilities and services, regional differences may be large and markets geographically segmented.

Although incorporating producer heterogeneity and pricing to market corrects the biases in the distance elasticity, there are other concerns regarding pricing behavior. As Hummels and Skiba (2004) have shown, there may be specific transportation costs, the presence of which leads firms to ship high-quality goods to a remote market (Alchian-Allen effect). Although our study extends the previous studies to account for variable markups, iceberg-type transportation costs are assumed and the Alchian-Allen effect is not taken into account. Investigating these effects is a topic for further research.

\section{References}

[1] Anderson, J., E. van Wincoop, 2003 Gravity with gravitas: a solution to the border puzzle, American Economic Review 93, 170-192.

[2] Anderson, J., E. van Wincoop, 2004 Trade costs, Journal of Economic Literature 42, $691-751$.

[3] Arkolakis, C., Costinot, A., A. Rodriguez-Clare, 2012 New trade models, same old gains? American Economic Review 102, 94-130.

[4] Atkeson, A., A. Burstein 2008 Pricing-to-market, trade costs, and international relative prices, American Economic Review 98, 1998-2031.

[5] Balistreri, E. J., Hillberry, R. H., T. F. Rutherford, 2011 Structural estimation and solution of international trade models with heterogeneous firms, Journal of International Economics 83, 95-108. 
[6] Bergin, P. R., Glick, R., A. M. Taylor, 2006 Productivity, tradability, and the long-run price puzzle, Journal of Monetary Economics 53, 2041-2066.

[7] Bernard, A. B., Eaton, J., Jensen, B., S. Kortum, 2003 Plants and productivity in international trade, American Economic Review 93, 1268-1290.

[8] Combes, P.-P., M. Lafourcade, 2005 Transport costs: measures, determinants, and regional policy implications for France, Journal of Economic Geography 5, 319-349.

[9] Crozet, M., P. Koenig, 2010 Structural gravity equations with intensive and extensive margins, Canadian Journal of Economics 43, 41-62.

[10] Crucini, M. J., Shintani, M., T. Tsuruga, 2010 The law of one price without the border: the role of distance versus sticky prices, Economic Journal 120, 462-480.

[11] Donaldson, D., 2010 Railroads of the Raj: estimating the impact of transportation infrastructure, NBER Working Paper 16487.

[12] Eaton, J., S. Kortum, 2002 Technology, geography, and trade, Econometrica 70, 17411779.

[13] Engel, C., J. H. Rogers, 1996 How wide is the border? American Economic Review 86, $1112-1125$.

[14] Ghironi, F., M. J. Melitz, 2005 International trade and macroeconomic dynamics with heterogeneous firms, Quarterly Journal of Economics 120, 865-915.

[15] Helpman, E., Melitz, M. J., Y. Rubinstein, 2008 Estimating trade flows: trading partners and trading volumes, Quarterly Journal of Economics 123, 441-487.

[16] Hummels, D., Skiba, A., 2004 Shipping the good apples out? An empirical confirmation of the Alchian-Allen conjecture, Journal of Political Economy 112, 1384-1402.

[17] Hummels, D., 2007 Transportation costs and international trade in the second era of globalization, Journal of Economic Perspectives 21, 131-154.

[18] Kano, K., Kano, T., K. Takechi, 2013 Exaggerated death of distance: revisiting distance effects on regional price dispersions, Journal of International Economics, forthcoming.

[19] Markusen, J., 2010 Putting per-capita income back into trade theory, NBER Working Paper No. 15903. 
[20] Melitz, M., G. Ottaviano, 2008 Market size, trade, and productivity, Review of Economic Studies 75, 295-316.

[21] Parsley, D. C., S.-J. Wei, 1996 Convergence to the law of one price without trade barriers or currency fluctuation, Quarterly Journal of Economics 111, 1211-1236.

[22] Parsley, D. C., S.-J. Wei 2001 Explaining the border effect: the role of exchange rate variability, shipping costs, and geography, Journal of International Economics 55, 87105.

[23] Simonovska, I., 2010 Income differences and prices of tradables, NBER Working Paper 16233.

[24] Simonovska, I., M. E. Waugh, 2010 The elasticity of trade: estimates and evidence, mimeo.

[25] Young, A., 1991 Learning by doing and the dynamic effects of international trade, Quarterly Journal of Economics 106, 369-405. 


\section{Table 1: Summary Statistics}

\begin{tabular}{ccccccccc}
\hline & Cabbages & Carrots & C-cabbages & Lettuce & Potatoes & S-mushrooms & Spinach & Welsh onions \\
\hline Average price (yen per kg) & 77.833 & 101.25 & 61.628 & 183.909 & 79.565 & 1113.627 & 496.372 & 382.099 \\
\hline Product entry & & & & & & & & \\
No. of varieties & 3 & 10 & 4 & 7 & 10 & 1 & 4 \\
No. of size categories & 63 & 62 & 50 & 71 & 50 & 74 & 17 & 103 \\
No. of grade categories & 34 & 66 & 50 & 46 & 93 & 55 & 85 & 58 \\
No. of producing prefectures & 47 & 46 & 46 & 43 & 47 & 44 & 47 & 47 \\
No. of wholesale markets & 47 & 47 & 47 & 47 & 47 & 47 & 47 \\
No. of distinct product entries & 1,207 & 1,186 & 1,001 & 903 & 1,423 & 909 & 551 & 1,115 \\
\hline Data truncation & & & & & & & \\
No. of $T_{i j}(\omega)=0$ or 1 & 369,343 & 198,129 & 241,871 & 239,703 & 264,280 & 476,919 & 466,337 & 547,272 \\
No. of $T_{i j}(\omega)=1$ & 15,841 & 8,395 & 10,803 & 11,565 & 10,921 & 11,845 & 15,977 & 14,874 \\
\hline
\end{tabular}


Table 2: Estimation Results

\begin{tabular}{|c|c|c|c|c|c|c|c|c|}
\hline & Cabbages & Carrots & C-cabbages & Lettuce & Potatoes & S-mushrooms & Spinach & Welsh onions \\
\hline \multicolumn{9}{|l|}{ Nonhomothetic } \\
\hline \multirow[t]{2}{*}{$\gamma$} & 0.46 & 0.627 & 0.655 & 0.687 & 0.613 & 0.768 & 0.666 & 0.566 \\
\hline & $(0.003)$ & $(0.006)$ & $(0.005)$ & $(0.006)$ & $(0.006)$ & $(0.008)$ & $(0.005)$ & $(0.006)$ \\
\hline \multirow[t]{2}{*}{$\theta$} & 2.013 & 1.169 & 1.585 & 1.203 & 1.272 & 2.329 & 1.667 & 1.98 \\
\hline & $(0.011)$ & $(0.009)$ & $(0.01)$ & $(0.008)$ & $(0.008)$ & $(0.008)$ & $(0.009)$ & $(0.008)$ \\
\hline \multirow[t]{2}{*}{$\rho$} & -0.83 & -0.868 & -0.809 & -0.854 & -0.775 & -0.624 & -0.845 & -0.831 \\
\hline & $(0.003)$ & $(0.003)$ & $(0.004)$ & $(0.003)$ & $(0.005)$ & $(0.005)$ & $(0.003)$ & $(0.003)$ \\
\hline log-likelihood & -19646.143 & -17034.691 & -13569.56 & -21025.084 & -24321.708 & -1779.114 & -18609.021 & -14368.145 \\
\hline \multicolumn{9}{|l|}{ CES } \\
\hline \multirow[t]{2}{*}{$\gamma$} & 0.287 & 0.345 & 0.382 & 0.402 & 0.335 & 0.49 & 0.402 & 0.354 \\
\hline & $(0.002)$ & $(0.003)$ & $(0.003)$ & $(0.003)$ & $(0.002)$ & $(0.004)$ & $(0.002)$ & $(0.002)$ \\
\hline \multirow[t]{2}{*}{$\epsilon$} & 3.326 & 2.123 & 2.78 & 2.126 & 2.381 & 3.688 & 2.83 & 3.292 \\
\hline & $(0.019)$ & $(0.014)$ & $(0.017)$ & $(0.014)$ & $(0.012)$ & $(0.028)$ & $(0.013)$ & $(0.018)$ \\
\hline \multirow[t]{2}{*}{$\rho$} & -0.86 & -0.884 & -0.83 & -0.874 & -0.793 & -0.546 & -0.848 & -0.848 \\
\hline & $(0.003)$ & $(0.003)$ & $(0.004)$ & $(0.004)$ & $(0.003)$ & $(0.005)$ & $(0.003)$ & $(0.003)$ \\
\hline log-likelihood & -24137.852 & -18563.794 & -15956.433 & -23317.952 & -26013.89 & -4383.126 & -22797.953 & -18319.21 \\
\hline \multicolumn{9}{|l|}{$\overline{\text { OLS }}$} \\
\hline$\gamma$ & 0.033 & 0.051 & 0.042 & 0.022 & 0.037 & 0.007 & 0.044 & 0.033 \\
\hline $\mathrm{N}$ & 369,343 & 198,129 & 241,871 & 239,703 & 264,280 & 476,919 & 466,337 & 547,272 \\
\hline $\mathrm{PCP}$ for $T_{i j}$ & 0.966 & 0.964 & 0.961 & 0.961 & 0.966 & 0.994 & 0.979 & 0.988 \\
\hline
\end{tabular}

Note: The numbers in parentheses are standard errors. All estimations include origin and destination dummies, origin and destination daily temperatures, the number of products in both equations, and wages for the selection equation. 


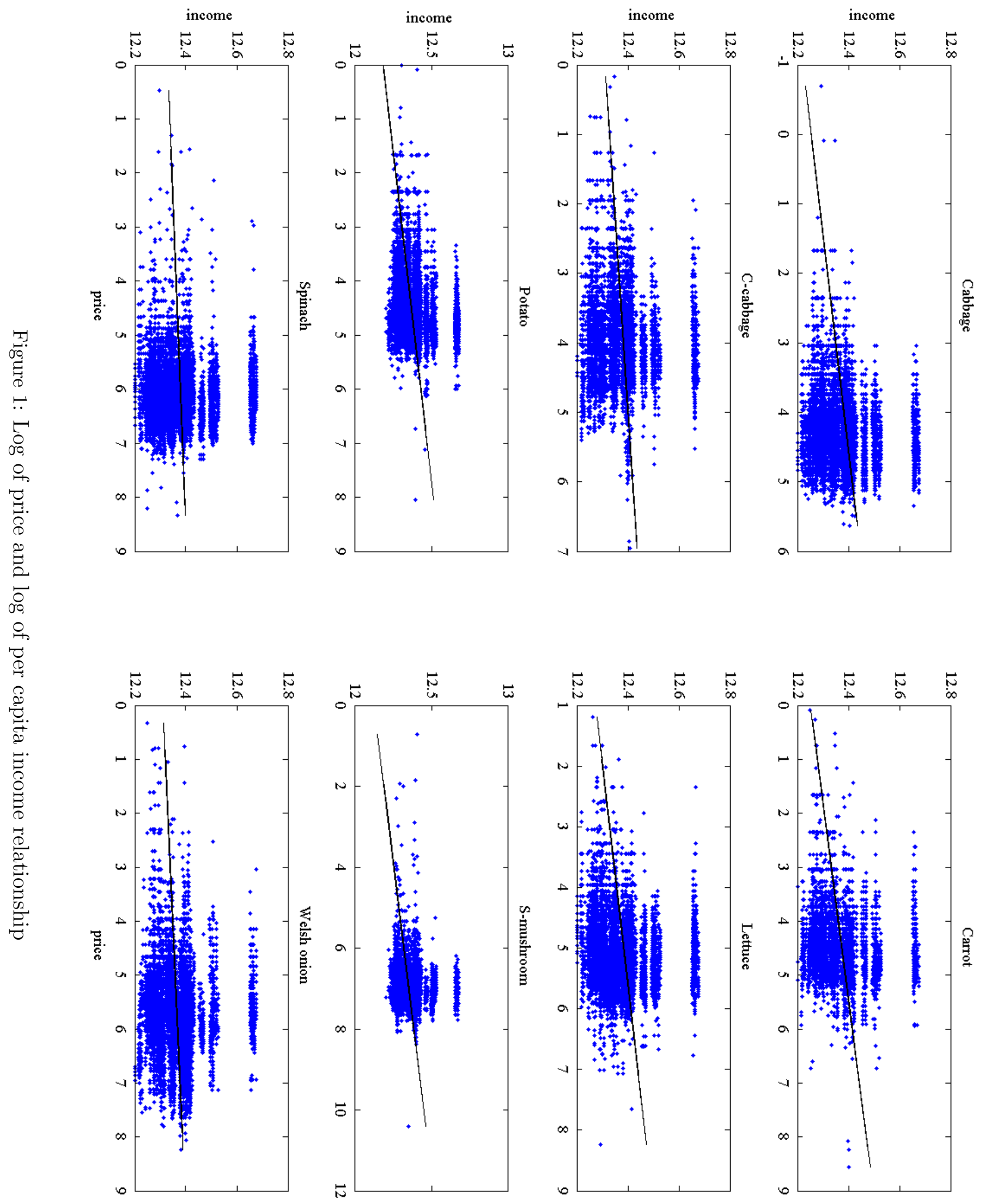






